\title{
Prophylactic effect of peptide vaccination against hepatocellular carcinoma associated with hepatitis $\mathbf{C}$ virus
}

\author{
NOBUKAZU KOMATSU ${ }^{1,3}$, SHIGERU YUTANI ${ }^{1,2}$, AKIRA YAMADA ${ }^{1,3}$, SHIGEKI SHICHIJO ${ }^{1}$, \\ KAZUMI YOSHIDA ${ }^{1}$, MINORU ITOU ${ }^{2}$, RYOKO KUROMATSU $^{2}$, TATSUYA IDE ${ }^{2}$, \\ MASATOSHI TANAKA ${ }^{2}$, MICHIO SATA ${ }^{2}$ and KYOGO ITOH ${ }^{1,3}$ \\ Departments of ${ }^{1}$ Immunology and Immunotherapy, and ${ }^{2}$ Internal Medicine, Kurume University School of Medicine, \\ ${ }^{3}$ Research Center for Innovative Cancer Therapy, Kurume University, Kurume, Fukuoka 830-0011, Japan
}

Received March 9, 2010; Accepted April 30, 2010

DOI: 10.3892/etm_00000097

\begin{abstract}
The purpose of the present study was to investigate the prophylactic effects of peptide vaccination against hepatocellular carcinoma (HCC) associated with hepatitis $\mathrm{C}$ virus (HCV). Two different Phase I clinical trials of HCV-derived peptides for $40 \mathrm{HCV}$-positive patients with chronic hepatitis (CH) and liver cirrhosis (LC) were conducted from November 2003 to November 2008. Among the patients, 39 (33 $\mathrm{CH}$ and 6 LC) received prolonged peptide vaccination with a median vaccination of 26 rounds (range 6-89). Median vaccination and observation periods were 16 months (range 2-61) and 47 months (range 10-69), respectively. Three $\mathrm{CH}$ and all $6 \mathrm{LC}$ patients had space-occupying lesions (SOLs) or a history of $\mathrm{HCC}$, respectively. HCC became detectable during the vaccination period in 2 of the $3 \mathrm{CH}$ patients with SOLs prior to vaccination. By contrast, $\mathrm{HCC}$ was undetectable throughout the vaccination period in the remaining 36 patients without SOLs. However, HCC became detectable in 4 of these 36 patients, i.e., $2 \mathrm{CH}$ patients at 46 and 29 months after the end of the vaccination period, and 2 LC patients at 49 and 18 months after the end of vaccination. The development of $\mathrm{HCC}$ was associated with a reduction in boosted $\mathrm{IgG}$ responses to the vaccinated peptides. These results may provide new information on peptide vaccination for $\mathrm{HCV}$-positive $\mathrm{CH}$ or LC patients lacking SOLs. Further studies are recommended to confirm the prophylactic effects of peptide vaccination against $\mathrm{HCC}$ associated with $\mathrm{HCV}$.
\end{abstract}

\section{Introduction}

Hepatitis C virus (HCV) is prevalent worldwide, with nearly 180 million infected individuals all carrying a risk of

Correspondence to: Dr Nobukazu Komatsu, Department of Immunology and Immunotherapy, Kurume University School of Medicine, Kurume University, 67 Asahi-machi, Kurume, Fukuoka 830-0011, Japan

E-mail: kom@med.kurume-u.ac.jp

Key words: hepatitis C virus, peptide vaccine, clinical study, cancer hepatocellular carcinoma (HCC) at later stages of the disease $(1,2)$. Interferon (IFN)-based therapies are effective in $80 \%$ of patients infected with the HCV2 and 3 genotypes and also in $50 \%$ of patients with the HCV1b genotype. However, IFN therapy has several limitations, including medical and physical contra-indications, adverse events and high cost (1-4). $\mathrm{HCV} 1 \mathrm{~b}$, the most frequently observed strain in Japan, is also a common strain in the US $(3,4)$.

Certain HCV patients show a spontaneous clearance of the virus along with acquisition of specific immunity, which encourages hopes of developing a clinically effective vaccine (5-7). However, the development of either prophylactic or therapeutic $\mathrm{HCV}$ vaccines is expected to be very difficult, since HCVs are very heterogeneous and their antigens are highly mutable (6-8). Indeed, in regards to a sustained viral response (SVR), no clinical benefit has yet been reported from $\mathrm{HCV}$ vaccines for either IFN-naive or IFN-resistant patients in recent clinical trials, including our own, in spite of successful immunological responses in a substantial number of patients (9-13). However, we recently identified a decrease in $\alpha$-fetoprotein (AFP), a biomarker for HCC, in a percentage of vaccinated patients who showed elevated AFP levels prior to vaccination (12). These results suggest that the $\mathrm{HCV}$ vaccine is effective as a cancer prophylaxis in chronic hepatitis $(\mathrm{CH})$ and liver cirrhosis (LC) patients. Subsequently, we report the results of a follow-up study of cancer prophylaxis in patients who had received a prolonged course of peptide vaccinations at our university.

\section{Materials and methods}

Patients. Patients received the HCV-derived peptides under one of two recent Phase I clinical studies held at the Kurume University Hospital; one study was conducted with HLA-A24+ patients (11) and the other with patients bearing multiple HLA-class I alleles (HLA-A2, -A3, -A11, -A24 -A26, -A31 or -A33) (12). The inclusion criteria were as follows: i) persistent HCV infection confirmed by serological HCV-RNA tests; ii) diagnosis of $\mathrm{CH}$ or $\mathrm{LC}$; iii) non-response to previous IFN-based treatment or refusal to receive such treatment; iv) no detectable HCC at the time of entry into the study; v) positive status for one of the following alleles: HLA-A2, -A3, 
-A11, -A24, -A26, -A31 or -A33; vi) an Eastern Cooperative Oncology Group performance status of $0-1$, age between 20 and 75 years and adequate hematological function (white blood cell count $\geq 2,400 / \mu \mathrm{l}$, hemoglobin level $\geq 8.0 \mathrm{~g} / \mathrm{dl}$ and platelet counts $\geq 50,000 / \mu \mathrm{l}$ ), renal function (serum creatinine $\leq 1.4 \mathrm{~g} / \mathrm{dl}$ ) and hepatic function (total bilirubin $<2.5 \mathrm{mg} / \mathrm{dl}$ ); and vii) negative status for hepatitis $B$ antigens. The protocols for both series were approved by the Institutional Ethics Review Boards of Kurume University, and complete written informed consent was obtained from all patients at the time of enrollment. A total of 40 patients entered one of the two protocols at our institution between November 2003 and November 2008. In addition, the 39 patients who received more than six vaccinations were included in this follow-up study.

Peptides and vaccination. For the first protocol, four peptides capable of inducing both cytotoxic T lymphocyte (CTL) and humoral responses $(\mathrm{IgG})$ in HLA-A24+ patients were provided for vaccination as previously reported (11). These four peptides were derived from well-conserved regions of HCV1b as follows: protein E1-derived peptide from positions 213 to 221 (E1 213-221); protein E2-derived peptide from positions 488 to 496 (E2 488-496); non-structural region 3-derived peptide from positions 1081 to 1090 (NS3 1081-1090); and non-structural region 5A-derived peptide from positions 2132 to 2140 (NS5A 2132-2140). For the second protocol, we used a peptide for vaccination derived from $\mathrm{HCV}$ core protein; this peptide was capable of inducing both CTL and humoral responses ( $\operatorname{IgG})$ in nearly all $\mathrm{HCV}$ patients with different HLA-class IA alleles in Japan $(12,14)$. This peptide originated from the HCV core protein at positions 35 to 44 (C 35-44), a well-known HLA-A2-restricted CTL epitope (15).

These five peptides were prepared under conditions of Good Manufacturing Practice by the American Peptide Company (San Diego, CA, USA). The peptide emulsion was injected into the subcutaneous region of the side of the abdomen or upper arm every 2 weeks from the 1st to the 24th vaccination, every 3 weeks from the 25th to the 48th vaccination and every 4 weeks thereafter. The first cycle consisted of six vaccinations; a second cycle of six vaccinations was conducted with patient consent in cases lacking any signs of severe toxicity. When patients wished to continue with the course of vaccinations, the series was extended, unless either disease progression or severe toxicity was observed.

Humoral responses to peptides. Peptide-specific IgG levels in the blood samples were measured using Luminex ${ }^{\circledR}$ systems as reported previously (11). Briefly, diluted plasma samples were incubated with peptide-coated microspheres. After the microspheres were washed, they were incubated with various antibodies (anti-human-IgG, -IgA, -IgM, -IgE, -IgG1, -IgG2, -IgG3 and -IgG4; purchased from Vector, Bethyl, Vector, Biosource, The Binding Site Ltd., Cappel, Cappel and The Binding Site Ltd., respectively). After being washed, the microspheres bound to each antibody were reacted with biotin-labeled detection antibody (Zymed or Cappel) and the corresponding R-phycoerythrin (Invitrogen) antibody, and the antibody levels were detected by a Luminex system as reported previously (11). All pre- and post-vaccination samples were measured simultaneously in order to avoid any possible biases associated with the in vitro assay. $\mathrm{IgG}$ against recombinant $\mathrm{HCV}$ core protein was also measured by means of a commercially available radioimmunoassay kit (SRL Laboratory, Tokyo, Japan).

Clinical laboratory data. Clinical laboratory values (e.g., serum ALT and AFP levels and blood platelet numbers) were measured by the Clinical Laboratory Division of the Kurume University Hospital. Quantitation of HCV-RNA, based on quantitative reverse transcription-polymerase chain reaction (qRT-PCR), was performed by a clinical lab company (SRL Laboratory).

\section{Results}

Patient characteristics and clinical responses. Thirty-nine $\mathrm{HCV}$-positive patients (33 $\mathrm{CH}$ and $6 \mathrm{LC}$ ) who had received more than six rounds of $\mathrm{HCV}$-derived peptide vaccinations were included in the analysis (Tables I-III). All patients, with the exception of 1 (pt. 16, HCV2a), were infected with HCVlb. At the time of entry into the study, 35 patients were non-responders to interferon-based therapy, and the remaining 4 patients refused treatment. All 6 LC patients had a history of $\mathrm{HCC}$ treatment, while $3 \mathrm{CH}$ patients had space-occupying hepatic lesions (SOLs) suspected of being cancerous at the time they entered the study. The median frequency of vaccination was 26 rounds (range 6-89), and the median duration of the vaccination period was 16 months (range 2-69). No severe toxicity was observed throughout the vaccination period, but grade 1 or 2 local inflammation at the injection site was observed in most cases. Twelve patients were still receiving vaccinations at the time of this writing (September 2009), and the course of vaccinations had been terminated in the remaining 27 patients. Eleven patients received IFN-based therapy combined with vaccination followed by the vaccination alone, and 9 patients received IFN-based therapy after the end of vaccination (Tables I-III).

A significant decrease in ALT level (<70\% ALT level at the end of vaccination or at the time of last vaccination vs. that before vaccination) was observed in 11 of 39 patients ( 7 of 28 patients treated with vaccination alone and 4 of 11 patients treated with vaccination alone followed by combined IFN-based therapy with vaccination). No significant decrease in platelet number $(<70 \%$ at the end of vaccination or at the time of last vaccination vs. that before vaccination) was found in any of the 28 patients who received vaccination alone, but an increase $(>130 \%)$ was noted in 1 patient. By contrast, a decrease in platelet number was observed in 4 of 11 patients with vaccination alone followed by combined IFN therapy. A significant decrease in the AFP level was found in 1 of 28 patients who received vaccination alone, whereas it was observed in 4 of 9 patients with vaccination alone followed by combined IFN therapy. HCV-RNA responders with $>1 \log$ decline were not found among the 28 patients who received the vaccination alone, while 4 of 11 patients who had received vaccination followed by combination therapy, including 3 sustained viral responders (SVR; pt. 1, 8 and 15), were HCV-RNA responders. As post-vaccination treatment, 9 patients received IFN-based therapy and only 1 (pt. 23) reached the status of SVR. The median observation period of the 39 patients was 47 months (range 10-69). 
Table I. Patient characteristics before vaccination.

\begin{tabular}{|c|c|c|c|c|c|c|c|c|}
\hline Patient & Age & Gender & Disease & Previous IFN & ALT & Plt & AFP & HCV-RNA \\
\hline 1 & 38 & M & $\mathrm{CH}$ & - & 139 & 11 & 8 & 465 \\
\hline 2 & 43 & M & CH (SOL) & IFN+RBV & 139 & 17 & 9 & 3,820 \\
\hline 3 & 52 & $\mathrm{~F}$ & LC (post HCC) & IFN+RBV & 105 & 9 & 173 & 651 \\
\hline 4 & 65 & M & LC (post HCC) & IFN+RBV & 292 & 5 & 7 & 4,030 \\
\hline 5 & 55 & M & $\mathrm{CH}$ & IFN+RBV & 119 & 9 & 11 & 4,290 \\
\hline 6 & 42 & M & $\mathrm{CH}$ & IFN+RBV & 73 & 12 & 4 & 621 \\
\hline 7 & 49 & M & $\mathrm{CH}$ & IFN+RBV & 48 & 13 & 3 & 1,010 \\
\hline 8 & 53 & $\mathrm{~F}$ & $\mathrm{CH}$ & IFN+RBV & 27 & 21 & 4 & 2,090 \\
\hline 9 & 70 & $\mathrm{~F}$ & $\mathrm{CH}$ & IFN+RBV & 38 & 12 & 12 & 2,200 \\
\hline 10 & 66 & M & $\mathrm{CH}$ & IFN+RBV & 154 & 15 & 11 & 139 \\
\hline 11 & 58 & $\mathrm{~F}$ & $\mathrm{CH}$ & IFN+RBV & 51 & 11 & 17 & 4,590 \\
\hline 12 & 50 & $\mathrm{~F}$ & $\mathrm{CH}$ & IFN+RBV & 62 & 14 & 10 & 1,730 \\
\hline 13 & 61 & $\mathrm{~F}$ & $\mathrm{CH}$ & IFN+RBV & 77 & 11 & 33 & 91 \\
\hline 14 & 51 & M & $\mathrm{CH}$ & IFN & 41 & 22 & 3 & 3,420 \\
\hline 15 & 50 & M & $\mathrm{CH}$ & IFN+RBV & 206 & 11 & 74 & 500 \\
\hline 16 & 71 & M & $\mathrm{CH}$ & $\mathrm{IFN+RBV}$ & 114 & 9 & 4 & 114 \\
\hline 17 & 51 & M & $\mathrm{CH}$ & IFN & 60 & 14 & 5 & 892 \\
\hline 18 & 60 & M & $\mathrm{CH}$ & IFN+RBV & 108 & 8 & 9 & 3,100 \\
\hline 19 & 49 & $\mathrm{~F}$ & $\mathrm{CH}$ & IFN+RBV & 129 & 16 & 44 & 2,480 \\
\hline 20 & 38 & M & $\mathrm{CH}$ & IFN+RBV & 358 & 6 & 29 & 2,870 \\
\hline 21 & 61 & $\mathrm{~F}$ & LC (post HCC) & IFN+RBV & 53 & 9 & 131 & 1,670 \\
\hline 22 & 58 & M & LC (post HCC) & RFA, IFN & 45 & 8 & 7 & 2,130 \\
\hline 23 & 71 & M & $\mathrm{CH}$ & IFN & 46 & 13 & 2 & 4,520 \\
\hline 24 & 70 & M & $\mathrm{CH}$ & IFN+RBV & 47 & 25 & 5 & 2,470 \\
\hline 25 & 68 & M & $\mathrm{CH}$ & IFN+RBV & 37 & 17 & 4 & 2,260 \\
\hline 26 & 64 & M & $\mathrm{CH}(\mathrm{SOL})$ & IFN+RBV & 60 & 13 & 13 & 3,630 \\
\hline 27 & 70 & M & CH (SOL) & IFN+RBV & 51 & 24 & 4 & 591 \\
\hline 28 & 62 & $\mathrm{~F}$ & $\mathrm{CH}$ & - & 24 & 19 & 5 & 583 \\
\hline 29 & 53 & $\mathrm{~F}$ & $\mathrm{CH}$ & IFN & 34 & 23 & 4 & 4,370 \\
\hline 30 & 63 & $\mathrm{~F}$ & $\mathrm{CH}$ & - & 73 & 12 & 3 & 59 \\
\hline 31 & 58 & $\mathrm{~F}$ & $\mathrm{CH}$ & IFN+RBV & 66 & 10 & 8 & 2,790 \\
\hline 32 & 63 & $\mathrm{~F}$ & $\mathrm{CH}$ & IFN+RBV & 52 & 12 & 3 & 2,230 \\
\hline 33 & 57 & $\mathrm{~F}$ & $\mathrm{CH}$ & IFN+RBV & 55 & 11 & 9 & 2,340 \\
\hline 34 & 58 & $\mathrm{~F}$ & $\mathrm{CH}$ & IFN & 80 & 12 & 7 & 2,150 \\
\hline 35 & 58 & $\mathrm{~F}$ & $\mathrm{CH}$ & IFN+RBV & 47 & 12 & 11 & 16,000 \\
\hline 36 & 61 & M & LC (post HCC) & IFN+RVB & 104 & 10 & 27 & 32,000 \\
\hline 37 & 58 & M & $\mathrm{CH}$ & - & 83 & 15 & 6 & 20 \\
\hline 38 & 60 & M & $\mathrm{CH}$ & IFN+RBV & 144 & 16 & 5 & 25,000 \\
\hline 39 & 73 & M & $\mathrm{LC}$ (post HCC) & IFN+RBV & 42 & 12 & 66 & 3,200 \\
\hline
\end{tabular}

HCV, hepatitis C virus; $\mathrm{CH}$, chronic hepatitis; SOL, space occupying lesions; LC, liver cirrhosis; HCC, hepatocellular carcinoma; IFN, interferon; RBV, ribavirin; ALT, alanine aminotransferase (IU/l); Plt, platelet numbers (x10 $\mathrm{ml})$; AFP, $\alpha$-fetoprotein (mg/ml); HCV-RNA, (kIU/ml).

Development of HCC. Under the circumstances described above, HCC became detectable during the vaccination period in 2 of $3 \mathrm{CH}$ patients (pt. 26 and 27) with SOLs prior to vaccination. By contrast, $\mathrm{HCC}$ was undetectable throughout the vaccination period in the remaining 36 patients without a SOL prior to vaccination. However, HCC was diagnosed in 4 of these 36 patients after the course of vaccination, i.e., in $2 \mathrm{CH}$ patients at 46 and 29 months after the end of vaccination (pt. 5 and 9), and in $2 \mathrm{LC}$ patients at 49 and 18 months after the end of vaccination (pt. 4 and 21). Three of these 4 patients received IFN-based therapy combined with vaccination (pt. 5), or after the end of vaccination (pt. 9 and 21) and showed no viral response (Tables I-III).

Antibody responses. We measured the patient IgG responses to each of the peptide vaccines in plasma samples before, 
Table II. Patient characteristics during vaccination.

\begin{tabular}{|c|c|c|c|c|c|c|c|c|}
\hline Patient & Rounds & Duration (m) & Later addition of IFN & ALT & Plt & AFP & HCV-RNA & Onset of $\mathrm{HCC}(\mathrm{m})$ \\
\hline 1 & 39 & 18 & + & 54 & 10 & 4 & - & \\
\hline 2 & 30 & 14 & + & 125 & 6 & 7 & 623 & \\
\hline 3 & 25 & 11 & + & 110 & 5 & 300 & 1,120 & \\
\hline 4 & 24 & 10 & - & 179 & 7 & 6 & 3,380 & \\
\hline 5 & 28 & 13 & + & 125 & 8 & 5 & 5,000 & \\
\hline 6 & 13 & 6 & - & 37 & 14 & 3 & 5,000 & \\
\hline 7 & 44 & 22 & + & 67 & 9 & 2 & 1,360 & \\
\hline 8 & 46 & 23 & + & 12 & 17 & 2 & $(-)$ & \\
\hline 9 & 18 & 8 & - & 29 & 15 & 10 & 4,430 & \\
\hline 10 & 17 & 7 & - & 176 & 15 & NA & 301 & \\
\hline 11 & 11 & 5 & - & 51 & 12 & 8 & 2,590 & \\
\hline 12 & 15 & 7 & - & 83 & 12 & 12 & 2,120 & \\
\hline 13 & 33 & 21 & + & 86 & 11 & 31 & 303 & \\
\hline 14 & 19 & 8 & - & 68 & 23 & 4 & 4,470 & \\
\hline 15 & 38 & 17 & + & 71 & 6 & 38 & - & \\
\hline 16 & 64 & 30 & + & 93 & 10 & 6 & $(+)$ & \\
\hline 17 & $89+$ & 61 & - & 39 & 14 & 6 & 1,600 & \\
\hline 18 & 35 & 16 & - & 51 & 10 & 8 & 3,470 & \\
\hline 19 & 26 & 15 & + & 193 & 10 & 28 & 2,890 & \\
\hline 20 & 43 & 41 & + & 262 & 6 & 22 & 16,000 & \\
\hline 21 & 22 & 12 & - & 63 & 9 & 134 & 3,870 & \\
\hline 22 & 28 & 20 & - & 26 & 7 & 12 & 8,000 & \\
\hline 23 & 6 & 2 & - & 51 & 13 & 2 & 2,310 & \\
\hline 24 & $39+$ & 35 & - & 108 & 22 & 2 & 32,000 & \\
\hline 25 & 15 & 8 & - & 32 & 19 & 3 & 1,540 & \\
\hline 26 & 19 & 10 & - & 68 & 13 & 39 & 3,650 & $+(10)$ \\
\hline 27 & 33 & 24 & - & 71 & 23 & 6 & 200 & $+(24)$ \\
\hline 28 & $33+$ & 28 & - & 24 & 20 & 3 & 1,600 & \\
\hline 29 & $29+$ & 28 & - & 39 & 27 & 3 & 10,000 & \\
\hline 30 & $33+$ & 28 & - & 39 & 13 & 2 & 80 & \\
\hline 31 & $32+$ & 26 & - & 67 & 11 & 7 & 4,000 & \\
\hline 32 & $32+$ & 25 & - & 67 & 11 & 4 & 16,000 & \\
\hline 33 & 17 & 9 & - & 44 & 12 & 11 & 5,000 & \\
\hline 34 & $25+$ & 21 & - & 55 & 12 & 7 & 2,000 & \\
\hline 35 & $16+$ & 13 & - & 67 & 9 & 19 & 8,000 & \\
\hline 36 & 10 & 16 & - & 120 & 11 & 28 & 16,000 & \\
\hline 37 & $23+$ & 16 & - & 49 & 16 & 7 & 40 & \\
\hline 38 & $14+$ & 14 & - & 162 & 13 & 7 & 25,000 & \\
\hline 39 & $16+$ & 10 & - & 42 & 13 & 59 & 3,200 & \\
\hline
\end{tabular}

HCV, hepatitis C virus; HCC, hepatocellular carcinoma; IFN, interferon; ALT, alanine aminotransferase (IU/l); Plt, platelet numbers (x 10 ml); AFP, $\alpha$-fetoprotein (mg/ml); HCV-RNA, (kIU/ml). m, months.

during and at the end of the vaccination period in all 39 patients. Moreover, when possible, we measured the IgG responses in patients after the end of the series of vaccinations $(n=10)$. Representative results of all 39 cases are shown in Fig. 1A-C. In the first protocol for HLA-A24+ patients $(n=13)$, an increase in anti-peptide $\operatorname{IgG}$ to E1 213-221, E2 488-496, NS3 1081-1090 and NS5A 2132-2140 peptides at the end of the peptide vaccination was observed in 0 of
7, 12 of 13, 4 of 13 and 9 of 13 patients who received the corresponding peptides, respectively (Fig. 1A). An increase in $\mathrm{IgG}$ reactive to at least one of the vaccination peptides was observed in all 13 patients. The increased $\mathrm{IgG}$ reactive to the E2-488 or NS5A-2132, but not to the NS3-1081 peptide, was sustained for $6,6,49,46,17,9,6$ and 6 months when the samples after the end of vaccination from pt. 1, 2, 4-6 and 9-11 were provided for measurement. 
Table III. Patient characteristics post vaccination.

\begin{tabular}{|c|c|c|c|}
\hline Patient & Post-vaccination IFN & $\begin{array}{l}\text { Total OP } \\
(\mathrm{m})\end{array}$ & $\begin{array}{c}\text { Onset of HCC } \\
\text { (m) }\end{array}$ \\
\hline 1 & & & 69 \\
\hline 2 & & & 67 \\
\hline 3 & & & 66 \\
\hline 4 & & $+(49)$ & 64 \\
\hline 5 & & $+(46)$ & 63 \\
\hline 6 & + & & 59 \\
\hline 7 & + & & 57 \\
\hline 8 & & & 56 \\
\hline 9 & + & $+(29)$ & 50 \\
\hline 10 & + & & 49 \\
\hline 11 & + & & 47 \\
\hline 12 & & & 58 \\
\hline 13 & & & 57 \\
\hline 14 & + & & 50 \\
\hline 15 & & & 64 \\
\hline 16 & & & 62 \\
\hline 17 & & & 61 \\
\hline 18 & + & & 58 \\
\hline 19 & & & 57 \\
\hline 20 & & & 52 \\
\hline 21 & + & $+(18)$ & 39 \\
\hline 22 & & & 28 \\
\hline 23 & + & & 35 \\
\hline 24 & & & 35 \\
\hline 25 & & & 32 \\
\hline 26 & & & 34 \\
\hline 27 & & & 29 \\
\hline 28 & & & 28 \\
\hline 29 & & & 28 \\
\hline 30 & & & 28 \\
\hline 31 & & & 26 \\
\hline 32 & & & 25 \\
\hline 33 & & & 22 \\
\hline 34 & & & 21 \\
\hline 35 & & & 11 \\
\hline 36 & & & 21 \\
\hline 37 & & & 21 \\
\hline 38 & & & 14 \\
\hline 39 & & & 10 \\
\hline
\end{tabular}

HCC, hepatocellular carcinoma; IFN, interferon; OP, observation periods. m, months.

In the second protocol for patients with different HLA-A alleles, the C 35-44 peptide was used for vaccination in all 26 patients, and an increase in anti-peptide $\operatorname{IgG}$ at the end of the peptide vaccination was observed in 22 of these patients (Fig. 1B and C). Ig isotypes and IgG subclasses of anti-C 35-44 peptide were also subjected to analysis in order to address whether Th1- or Th2-type immune responses were induced by peptide vaccination in the 26 patients who received C $35-44$ peptide vaccinations. We found that all Ig isotypes (IgM, IgA, $\mathrm{IgG}$ and $\mathrm{IgE}$ ), as well as all $\mathrm{IgG}$ subclasses (IgG1 to $\mathrm{IgG} 4$ ), were augmented by vaccination in all 22 patients exhibiting elevated IgG. Four representative cases (pt. 12, 19, 22 and 27) are shown in Fig. 2.

These results indicate that IgG responses to E2 488-496, NS5A 2132-2140 and C 35-44 peptides were boosted in the majority of vaccinated patients, i.e., IgG responses to NS3 1081-1090 were boosted in half of the patients, whereas the IgG response to the E1 213-221 peptide was not boosted in any of the patients. These results are consistent with those reported previously using samples from our Phase I study $(11,12)$.

Measurement of cellular responses using post-vaccination samples was not carried out in this study, primarily due to the limited number of available peripheral blood mononuclear cells, although an increase in cellular responses to at least one of the vaccinated peptides during the Phase I studies was observed in the majority of patients, as reported previously $(11,12)$.

Development of HCC and antibody responses. We then addressed the relationship between the development of HCC and patient immune responses.

HCC became detectable during the course of vaccination in 2 of $3 \mathrm{CH}$ patients (pt. 26 and 27) with SOLs prior to vaccination. In these two patients, humoral responses to the vaccinated peptides were well augmented in the postvaccination samples (Figs. 1 and 2). In the other patient (pt. 2) with a SOL but without HCC, the humoral responses to the vaccinated peptides were also augmented (Fig. 1).

HCC was undetectable in the remaining 36 patients throughout the vaccination period, but it became detectable in 4 patients post-vaccination, i.e., in $2 \mathrm{CH}$ patients at 46 and 29 months after the end of the vaccination (pt. 5 and 9), and in $2 \mathrm{LC}$ patients at 49 and 18 months after the end of the vaccination (pt. 4 and 21). The development of HCC in these four cases was associated with a disappearance of vaccination-induced humoral responses. Namely, the $\mathrm{IgG}$ boosting effect reactive to NS3-1081 and NS5A-2132, but not to E2-488, disappeared in pt. 4 and 5 when HCC became detectable 49 and 46 months after the end of vaccination, respectively (Fig. 1A). The IgG boosting effect reactive to NS5A-2132 and E2-488 also disappeared in pt. 9 when HCC became detectable 29 months after the end of vaccination. Similarly, the IgG boosting effect to the $\mathrm{C}-35$ peptide in pt. 21 disappeared by the time HCC developed, i.e., 18 months after the end of the vaccination period (Fig. 1B).

The results presented above suggest an association between HCC development and the weakening of boosted $\mathrm{IgG}$ responses to the peptides used for vaccination. We then addressed whether IgG responses to the HCV core protein had any association with HCC development in pt. 21, who received core protein-derived peptide C-35 (Fig. 3). The increase in $\mathrm{IgG}$ levels in response to the $\mathrm{HCV}$ core protein was reduced to the pre-vaccination baseline level at the time of HCC development. The IgG responses in the remaining 3 patients who did not receive the $\mathrm{C}-35$ peptide were also measured. As expected, there was no association in these 3 patients between $\operatorname{IgG}$ titers raised against the $\mathrm{HCV}$ core protein and $\mathrm{HCC}$ development (Fig. 3). 
A
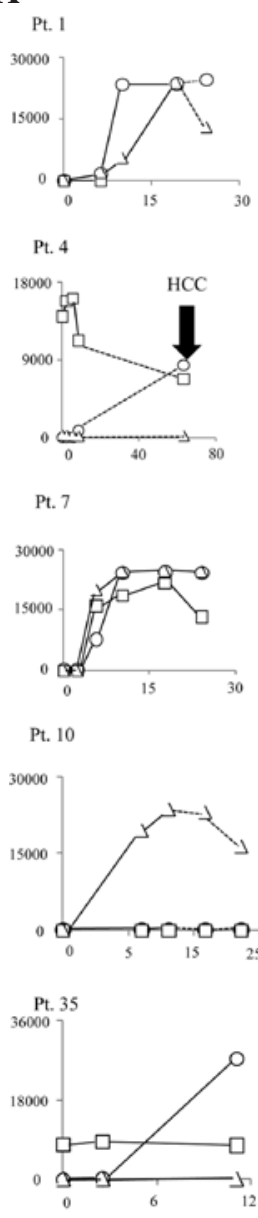

B
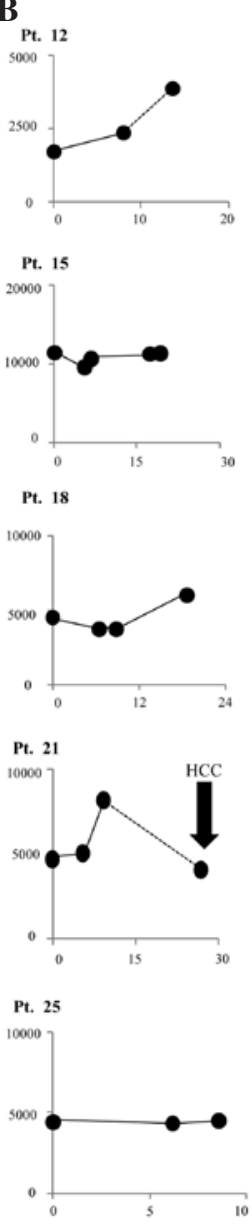
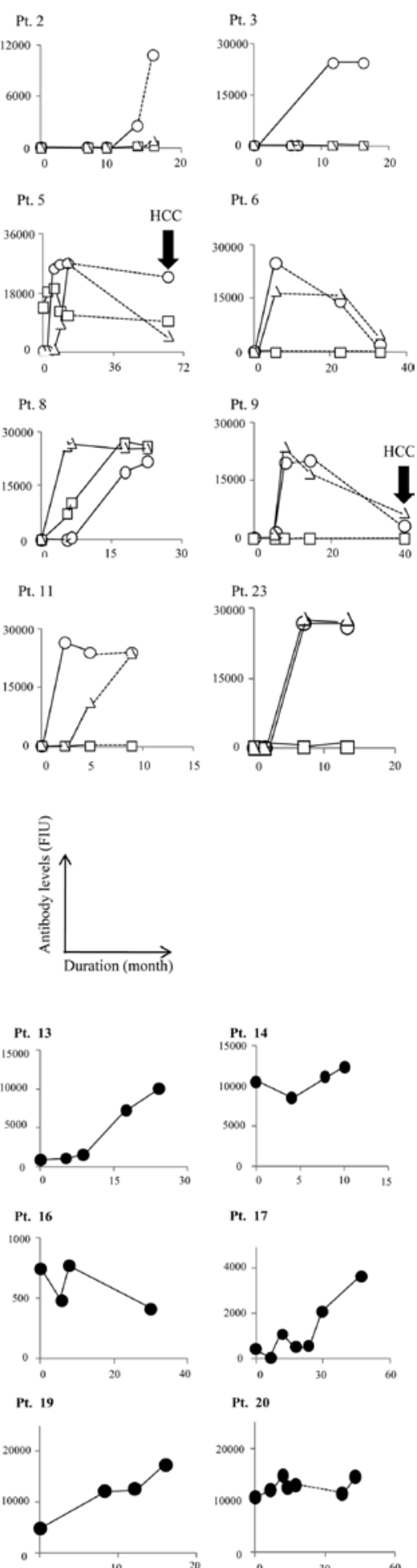

Pt. 20
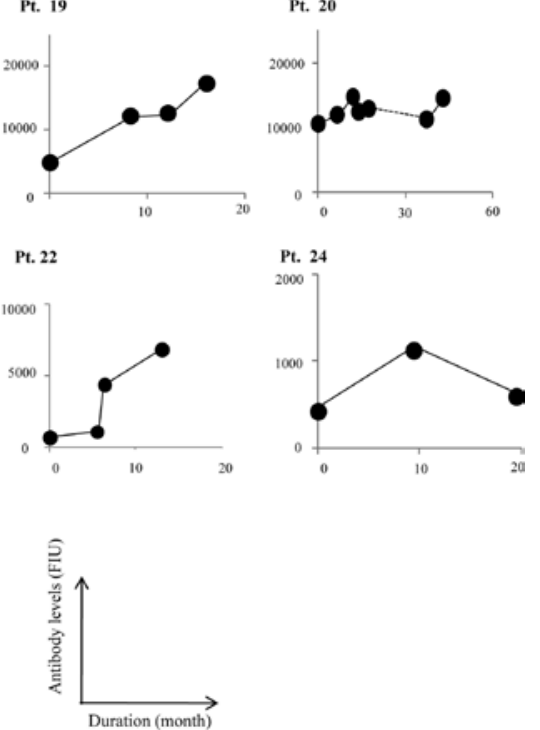

C
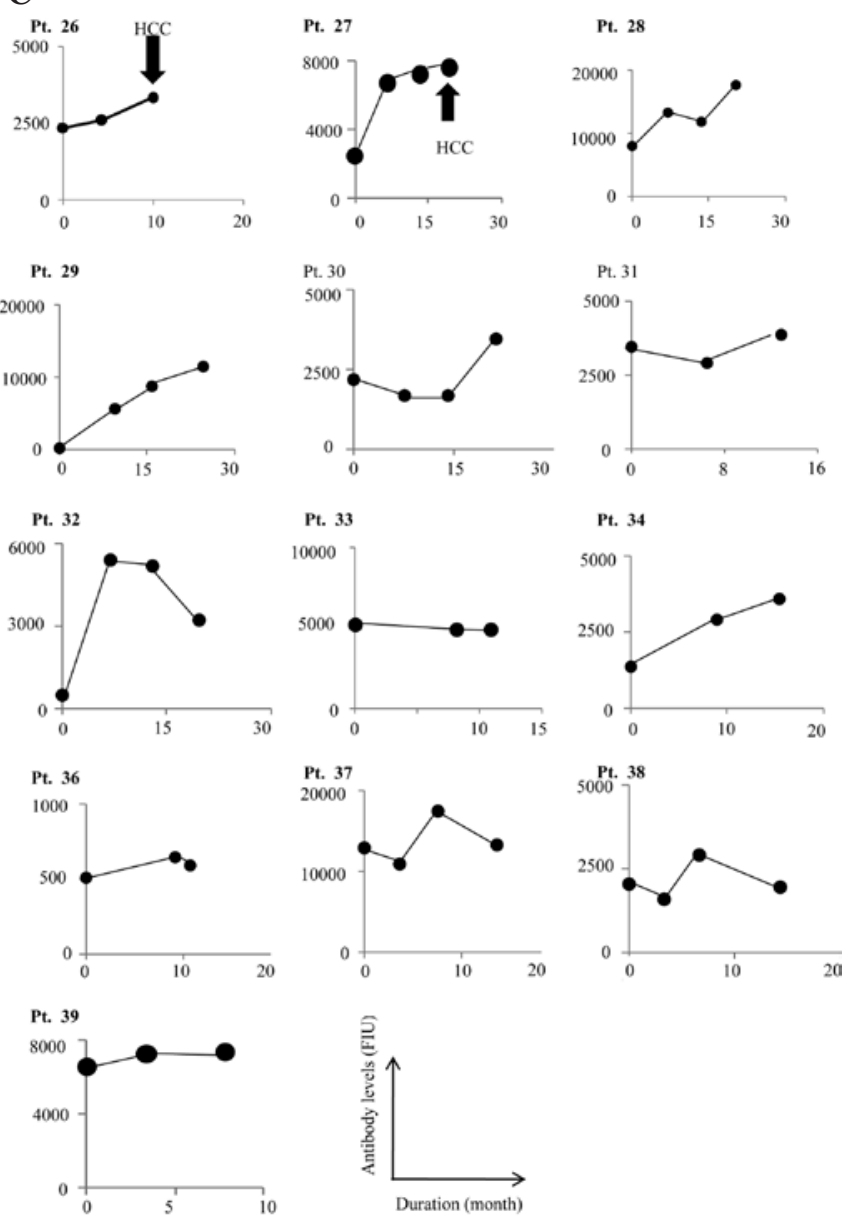

Figure 1 . IgG responses to peptides. Kinetic measurement of $\mathrm{IgG}$ responses to each of the peptides used for vaccination in plasma samples before, during, and at the end of the vaccination period, as well as in samples obtained post-vaccination, when available. The vertical column indicates the levels of antibody expressed as fluorescence intensity units (FIU), as reported previously (11). The horizontal column indicates the duration of vaccination (and that of observation after the end of vaccination (-----). (A) $\bigcirc-\bigcirc, \mathrm{IgG}$ to E2 488-496; $\square-\square$, IgG to NS3 1081-1090; $\triangle-\triangle$, IgG to NS5A 2132-2140 peptides. (B and C) •-•, IgG to C $35-44$ peptide.

\section{Discussion}

The reported annual occurrence rates of $\mathrm{HCC}$ in $\mathrm{CH}$ patients, LC patients, non-responders and patients with a history of HCC treatment vary largely from <1-5, 5-8, 1-7 and 10-20\% per year, respectively, depending on the population studied (5,16-22). HCC has been shown to develop even in sustained viral responders at a rate of $<1-2 \%$ per year, depending on the population studied $(23,24)$. Only 39 vaccinated patients were included in the present follow-up study; thus, information regarding general $\mathrm{HCC}$ occurrence and recurrence rates at the Kurume University Hospital could be useful for gaining a better understanding of the results of this study. The 2-year occurrence rate of $\mathrm{HCC}$ in non-vaccinated $\mathrm{HCV} \mathrm{b}^{+}$patients with platelet numbers of $<130,000$ per $\mathrm{mm}^{3}$ (stages F3 and F4) (5) who failed to respond to IFN-ribavirin therapy was 19\%, while the 2-year recurrence rate in non-vaccinated $\mathrm{HCVlb}^{+}$ patients after a history of HCC treatment was $47.5 \%$ at Kurume University Hospital (Sata et al, unpublished data). In this study, 16 and 6 patients were matched to the former and 
A

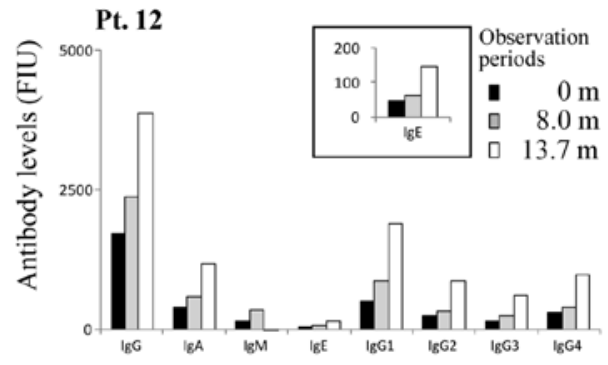

C

Pt. 22

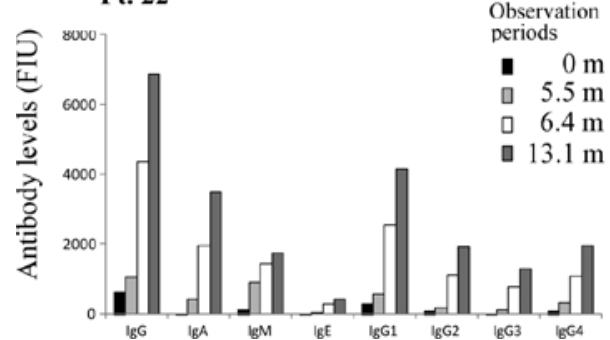

B

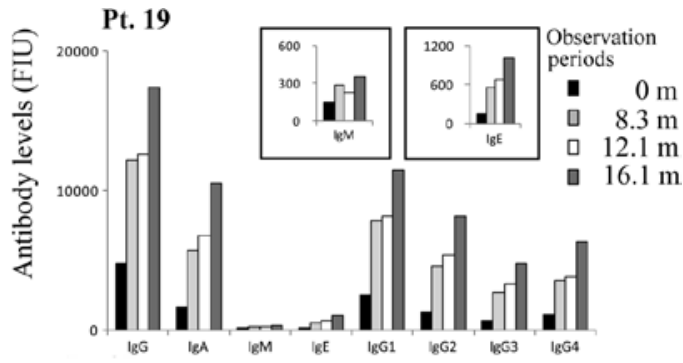

D

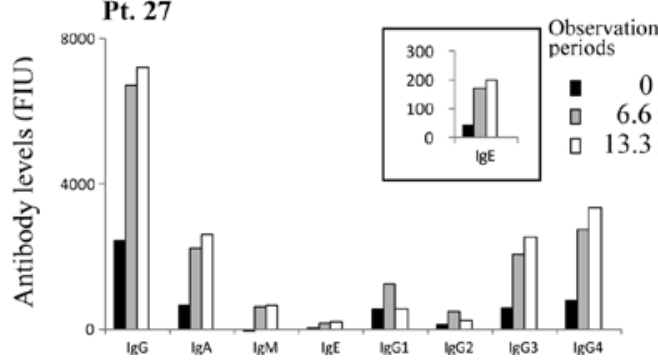

Figure 2. Isotypes and IgG subclasses. Kinetic measurement of Ig isotypes and $\operatorname{IgG}$ subclasses of anti-C 35-44 peptide was also studied in 22 patients. All isotypes (IgM, $\operatorname{IgA}$, $\operatorname{IgG}$ and $\operatorname{IgE}$ ), as well as all $\mathrm{IgG}$ subclasses (IgG1 to $\mathrm{IgG} 4$ ), were augmented by the C 35-44 vaccination in all 22 patients in whom $\operatorname{IgG}$ was elevated, as shown in Fig. 1. Four representative cases (pt. 12, 19, 22 and 27) are shown here.
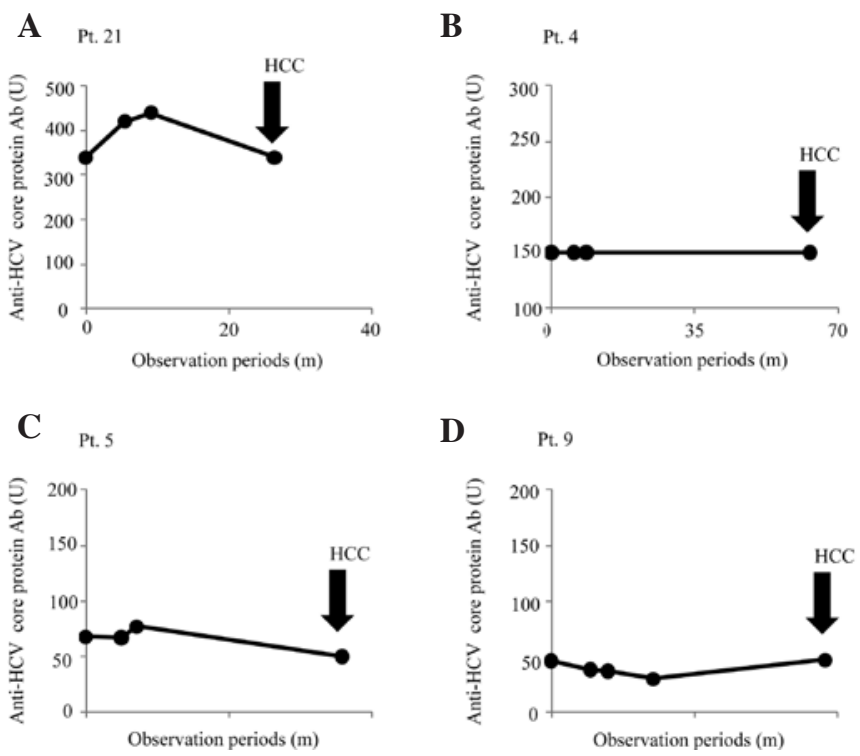

Figure 3. IgG responses to HCV core protein. Kinetic measurement of IgG responses against recombinant $\mathrm{HCV}$ core protein in plasma samples before, during and at the end of the vaccination, as well as after the end of vaccination in 4 patients who had developed HCC post-vaccination. The vertical column indicates the determined antibody level.

latter group of patients, respectively. A median observation period for these 22 patients after the initiation of vaccination was 55 months (range 10-69). HCC was undetectable in all of these 22 patients at least 30 months after the initiation of peptide vaccination. However, HCC became detectable 59, 58, 37 and 30 months after the initiation in pt. 4, 5, 9 and 21, respectively. With regard to post-vaccination, HCC became detectable at 49, 46, 29 and 18 months in pt. 4, 5, 9 and 21, respectively. These results suggest that peptide vaccination induced prophylaxis against HCC associated with HCV.

By contrast, HCC developed in 2 (pt. 26 and 27) of $3 \mathrm{CH}$ patients with SOLs suspected of being cancerous at the start of the vaccination period (Tables I-III), suggesting that the peptide vaccine has no prophylactic effects in patients with pre-existing SOLs.

Our results suggest that the vaccination-induced increase in peptide-specific IgG lasts for 6 months after the end of a vaccination course. However, the duration of this response appears to depend on the specific peptides used for vaccination, as well as on the dose and frequency of vaccination. Thus, these issues need to be further investigated in future clinical trials with larger sample sizes. Moreover, HCC development was associated with a reduction in boosted immune responses showing reactivity to specific peptide vaccines, as well as to the corresponding core protein. Therefore, $\mathrm{IgG}$ reactivity to peptides used for vaccination may serve as a biomarker for predicting $\mathrm{HCC}$ development in $\mathrm{HCV}$-positive patients who have received a peptide vaccine. It should be noted that only 4 patients were available for this aspect of the present study and therefore, further investigation is required in order to confirm our results. In addition, the biological roles of the peptide antibodies remain unclear at the present time and should be elucidated by future investigation.

Th1-type immune responses are thought to be involved in chronic-phase liver damage $(25,26)$. Nelson et al found that interleukin-10 treatment resulted in the normalization of ALT levels in 19 of $22 \mathrm{CH}$ patients who had been non-responders to INF-based treatment (27). Interleukin-10 promotes the production of $\operatorname{IgA}$, IgG1 and IgG3 $(28,29)$. We demonstrated an increase in all three of these Ig isotypes in post-vaccination samples, suggesting that the Th2-type immune response is indeed boosted by vaccination.

We also measured the CTL activity of PBMCs during the course of vaccination; our results were reported elsewhere $(11,12)$. However, CTL activity was not measured in the post-vaccination follow-up study primarily due to the limited number of available samples.

In previously reported $\mathrm{HCV}$ vaccine trials (9-13), as well as in the present follow-up study, there has yet to be a sustained 
viral responder, regardless of the fact that successful immune responses have been induced in a substantial number of patients. The well-recognized difficulty of developing either prophylactic or therapeutic $\mathrm{HCV}$ vaccines largely results from viral heterogeneity and mutability (6-8). In addition, many studies have demonstrated suppressed or imbalanced immunity in $\mathrm{CH}$ or LC patients with $\mathrm{HCV}(25,26,30)$. Previous and present results, when taken together, suggest that developing an HCV vaccine to induce SVR as a primary endpoint will not be feasible until novel scientific breakthroughs in this field have been made. However, HCV peptide vaccines may augment both cellular and humoral responses against HCV-derived peptides in a large percentage of patients. This potential of peptide vaccines provides some hope that boosted specific immunity eliminates cancerous liver cells infected with $\mathrm{HCV}$, which in turn may result in prevention or delay of HCC development associated with HCV. Indeed, the results of the present study support this hypothesis. Further clinical studies are required to confirm whether or not peptide vaccination using CTL epitopes derived from $\mathrm{HCV}$ protein are effective for prophylaxis against $\mathrm{HCC}$ in $\mathrm{HCV}$-positive patients without SOL.

\section{Acknowledgements}

This study was supported in part by Grants-in-Aid from the Ministry of Education, Science, Sports and Culture of Japan to the Research Center of Innovative Cancer Therapy of the 21st Century Center of Excellence (COE) Program for Medical Science, and to Toshi-area Research.

\section{References}

1. World Health Organization (WHO) Hepatitis C. 2006. Available at: http://www.who.int/vaccine_research/diseases/viral_cancers/ en/index 2.html\#disease\%20burden

2. Chander G, Sulkowski MS, Jenckes MW, Torbenson MS, Herlong HF, Bass EB and Gebo KA: Treatment of chronic hepatitis C: a systematic review. Hepatology 36: S135-S144, 2002.

3. Kato N, Hijikata M, Ootsuyama Y, Nakagawa M, Ohkoshi S and Sugimura T: Molecular cloning of the human hepatitis $\mathrm{C}$ virus genome from Japanese patients with non-A, non-B hepatitis. Proc Natl Acad Sci USA 87: 9524-9528, 1990.

4. Blatt LM, Mutchnick MG, Tong MJ, et al: Assessment of hepatitis $\mathrm{C}$ virus RNA and genotype from 6807 patients with chronic hepatitis C in the United States. J Viral Hepat 7: 196-202, 2000.

5. Yoshida H, Shiratori Y, Moriyama M, et al: Interferon therapy reduces the risk for hepatocellular carcinoma: national surveillance program of cirrhotic and noncirrhotic patients with chronic hepatitis $\mathrm{C}$ in Japan. IHIT Study Group. Inhibition of Hepatocarcinogenesis by Interferon Therapy. Ann Intern Med 131: 174-181, 1999.

6. Houghton $\mathrm{M}$ and Abrignani S: Prospects for a vaccine against the hepatitis C virus. Nature 436: 961-966, 2005.

7. Strickland GT, EI-Kamary SS, Klenerman P and Nicosia A: Hepatitis C vaccine: supply and demand. Lancet Infect Dis 8: 379-386, 2008

8. Bowen DG and Walker CM: Mutational escape from CD8+ $\mathrm{T}$ cell immunity: HCV evolution, from chimpanzees to man. J Exp Med 201: 1709-1714, 2005.

9. Schlaphoff V, Klade CS, Jilma B, et al: Functional and phenotypic characterization of peptide-vaccine-induced $\mathrm{HCV}$-specific $\mathrm{CD} 8+\mathrm{T}$ cells in healthy individuals and chronic hepatitis $\mathrm{C}$ patients. Vaccine 25: 6793-6806, 2007.

10. Klade CS, Wedemeyer H, Berg T, et al: Therapeutic vaccination of chronic hepatitis $\mathrm{C}$ nonresponder patients with the peptide vaccine IC41. Gastroenterology 134: 1385-1395, 2008.
11. Yutani S, Yamada A, Yoshida K, et al: Phase I clinical study of a personalized peptide vaccination for patients infected with hepatitis $\mathrm{C}$ virus (HCV) $1 \mathrm{~b}$ who failed to respond to interferonbased therapy. Vaccine 25: 7429-7435, 2007.

12. Yutani S, Komatsu N, Shichijo S, et al: Phase I clinical study of a peptide vaccination for hepatitis $\mathrm{C}$ virus-infected patients with different HLA-class I-A alleles. Cancer Science 100: 1935-1942, 2009.

13. Leroux-Roels G, Batens AH, Desombere I, et al: Immunogenicity and tolerability of intradermal administration of an $\mathrm{HCV}$ E1-based vaccine candidate in healthy volunteers and patients with resolved or ongoing chronic HCV infection. Hum Vaccin 1: 61-65, 2005.

14. Niu Y, Terasaki Y, Komatsu N, et al: Identification of peptides applicable as vaccines for HLA-A26-positive cancer patients. Cancer Science 100: 2167-2174, 2009.

15. Cerny A, McHutchison JG, Pasquinelli C, et al: Cytotoxic T lymphocyte response to hepatitis $\mathrm{C}$ virus-derived peptides containing the HLA A2.1 binding motif. J Clin Invest 95: 521-530, 1995.

16. Kiyosawa K, Umemura T, Ichijo T, et al: Hepatocellular carcinoma: recent trends in Japan. Gastroenterology 127: S17-S26, 2004.

17. Taura K, Ikai I, Hatano E, et al: Influence of coexisting cirrhosis on outcomes after partial hepatic resection for hepatocellular carcinoma fulfilling the Milan criteria: an analysis of 293 patients. Surgery 142: 685-694, 2007.

18. Shiratori Y, Shiina S, Teratani T, et al: Interferon therapy after tumor ablation improves prognosis in patients with hepatocellular carcinoma associated with hepatitis $\mathrm{C}$ virus. Ann Intern Med 138: 299-306, 2003.

19. Kubo M, Sakaguchi Y, Chung H, et al: Long-term interferon maintenance therapy improves survival in patients with HCV-related hepatocellular carcinoma after curative radiofrequency ablation. A matched case-control study. Oncology 72: 132-138, 2007.

20. Kim JH, Han KH, Lee KS, et al: Efficacy and long term follow up of combination therapy with interferon alpha and ribavirin for chronic hepatitis C in Korea. Yonsei Medical Journal 47: 793-798, 2006.

21. Arase Y, Ikeda K, Suzuki F, et al: Long term outcome after interferon therapy in elderly patients with chronic hepatitis C. Intervirology 50: 16-23, 2007.

22. Ikeda K, Saitoh S, Arase Y, et al: Effect of interferon therapy on hepatocellular carcinogenesis in patients with chronic hepatitis type C: a long-term observation study of 1,643 patients using statistical bias correction with proportional hazard analysis. Hepatology 29: 1124-1130, 1999.

23. Toyoda H, Kumada T, Tokuda A, et al: Long-term follow-up of sustained responders to interferon therapy in patients with chronic hepatitis C. J Viral Hepatitis 7: 414-419, 2007.

24. Okanoue T, Itoh Y, Minami M, et al: Interferon therapy lowers the rate of progression to hepatocellular carcinoma in chronic hepatitis $\mathrm{C}$ but not significantly in an advanced stage: a retrospective study in 1148 patients. J Hepatol 30: 643-649, 1999.

25. Bertoketti A, Bertoletti A, D'Elios MM, et al: Different cytokine profiles of intrahepatic T cells in chronic hepatitis B and hepatitis C virus infections. Gastroenterology 112: 193-199, 1997.

26. McGuinness PH, Painter D, Davies S and McCaughan GW: Increases in intrahepatic CD68 positive cells, MAC387 positive cells and proinflammatory cytokines (particularly interleukin 18) in chronic hepatitis C infection. Gut 46: 260-269, 2000.

27. Nelson DR, Lauwers GY, Lau JY and Davis GL: Interleukin 10 treatment reduces fibrosis in patients with chronic hepatitis $\mathrm{C}$ : a pilot trial of interferon nonresponders. Gastroenterology 118: 655-660, 2000.

28. Brière F, Servet-Delprat C, Bridon JM, Saint-Remy JM and Banchereau J: Human interleukin 10 induces naive surface immunoglobulin D+ (sIgD+) B cells to secrete IgG1 and IgG3. J Exp Med 179: 757-762, 1994.

29. Defrance T, Vanbervliet B, Brière F, et al: Interleukin 10 and transforming growth factor beta cooperate to induce anti-CD40activated naive human B cells to secrete immunoglobulin A. J Exp Med 175: 671-682, 1992.

30. Rushbrook SM, Ward SM, Unitt E, et al: Regulatory T cells suppress in vitro proliferation of virus-specific CD8+ T cells during persistent hepatitis $\mathrm{C}$ virus infection. J Virol 79: 7852-7859, 2005. 